\title{
Colloidal Mobilization and Fate of Trace Heavy Metals in Semi-Saturated Artificial Soil (OECD) Irrigated with Treated Wastewater
}

\author{
Ludovico Pontoni ${ }^{1,2,4, *}$, Eric D. van Hullebusch ${ }^{2,3}$, Yoan Pechaud ${ }^{2}$, Massimiliano Fabbricino ${ }^{4}$, \\ Giovanni Esposito ${ }^{1}$ and Francesco Pirozzi ${ }^{4}$ \\ 1 Department of Civil and Mechanical Engineering, University of Cassino and Southern Lazio, \\ Via Di Biasio 43, 03043 Cassino, Italy; giovanni.esposito@unicas.it \\ 2 Université Paris-Est, Laboratoire Géomatériaux et Environnement (EA 4508), UPEM, \\ 77454 Marne-la-Vallée, France; e.vanhullebusch@unesco-ihe.org (E.D.v.H.); Yoan.Pechaud@u-pem.fr (Y.P.) \\ 3 Department of Environmental Engineering and Water Technology, UNESCO-IHE Institute for \\ Water Education, Westvest 7, 2611 AX Delft, The Netherlands \\ 4 Department of Civil, Architectural and Environmental Engineering, University of Naples Federico II, \\ Via Claudio 21, 80125 Naples, Italy; fabbrici@unina.it (M.F.); francesco.pirozzi@unina.it (F.P.) \\ * Correspondence: ludovico.pontoni@unina.it; Tel.: +39-081-768-3425
}

Academic Editor: Marc A. Rosen

Received: 17 October 2016; Accepted: 29 November 2016; Published: 2 December 2016

\begin{abstract}
The mobility of selected heavy metals in trace concentrations was investigated in a standard OECD soil irrigated with the effluent of a real municipal wastewater treatment plant. While $\mathrm{Cd}, \mathrm{Cu}$ and $\mathrm{Ni}$ accumulation-migration patterns were mainly influenced by the mobility of colloids generated from soil organic and inorganic matter, Zn mobility was more influenced by the wastewater content of dissolved organic matter and by its salinity. Metal accumulation caused by interaction with colloids resulted in contamination peaks both in different zones of the soil column and in the leaching solution. The release of metals in the leachate was correlated to the contemporary release of silicates from kaolinite and dissolved organic matter, identified through UV absorbance and chemical oxygen demand monitoring. The hypothesized colloidal mobilization was confirmed by spectroscopic studies. The highly heterogeneous complexes of organic and inorganic molecules responsible for metal transport through soil appeared to be structured in highly stable micellar aggregates.
\end{abstract}

Keywords: colloidal mobilization of HMs; fate of trace metals; humic substances; mineral organic associations; soil organic matter

\section{Introduction}

The recovery and reuse of wastewater in agriculture is a promising strategy to face water scarcity issues [1]. Treated wastewater is a "new" water resource, which can positively contribute to the agriculture sustainability. The advantage consists in restoring the organic and inorganic nutrient pools of soils, solving, at the same time, water shortage and wastewater discharge problems [2], especially in arid and semi-arid regions [3]. However, wastewater reuse for irrigation purposes can represent a serious threat to environmental quality [4]. The presence of trace level concentrations of potentially harmful pollutants is in fact permitted in irrigation water by existing regulations all over the world, since it does not represent a short-term hazard for environmental quality. Nonetheless some compounds, such as heavy metals (HMs), can accumulate in the soil through the years [5], finally reaching the crops and eventually entering the food chain [6].

The fate of HMs in soils is difficult to predict. Mechanisms of mobility through the different soils horizons are, in fact, extremely diverse, being related to: (i) the soil physical-chemical nature; (ii) the 
soil-water retention capacity; and (iii) the fluid transmission characteristics. Clearly both wastewater and soil composition have a fundamental role in the complex dynamics that regulate HMs mobility through the different layers. Particularly, organic matter is considered to have a crucial effect, by greatly influencing the retention and the transportation of HMs and other micro-pollutants. Organic molecules are present both in the wastewater and the soil matrix. The presence of organic matter can either enhance, when dissolved (DOM), or retard, when bound to the soil (SOM), the transport of inorganic pollutants [7]. HMs and contaminants in general are not only partitioned between the solid immobile and the water mobile phases. Colloids and nanoparticles act as a third mobile phase, with their own rheological properties and velocity [8]. This third mobile phase can be organic, inorganic or composed by mineral organic associations (MOAs) [9]. Three criteria must be met for colloid-facilitated contaminant transport: (i) colloids must be present; (ii) contaminants must interact with colloids; and (iii) colloids and associated contaminants must be transported through the aquifer [10].

Studying the interaction of HMs in "artificial" water solutions with the standard OECD soil, a novel HMs transport pattern was recently proposed [11]. A multi-component mechanism was assumed including: (i) the interaction of HMs with the colloidal phase of the soil; (ii) the slow and constant release of small molecular weight ligands detaching from the soil immobile matrix; (iii) the transportation of HMs through the soil by these low molecular weight chaperon molecules. To further improve the knowledge of the proposed mechanism, a deeper understanding of the structural composition of soil organic matter would be required. Soil organic matter, in fact, is constantly under study, and its structural composition is subject of debates among the scientific community [12]. The classical idea of a class of unknown polymeric macromolecules-namely Humic Acids (HA), Fulvic Acids (FA) and humin-is going to be surpassed by the new concept which considers humic substances to be supramolecular aggregates of small organic compounds, held together by weak dispersive forces [12]. In the light of this theory, soil released chaperone molecules or their aggregates can have different characteristics in terms of chemical structure and molecular weights distribution. According to these characteristics, they can have different moving rates through the porous media, as well as different affinity and selectivity with metals. As a consequence of the existing heterogeneity among colloids and chaperon molecules generated in soil, the "three phase model" becomes a "multiphase model". Each metal is preferentially transported by one or more phases and moves through soil with a velocity that is governed by the phase interaction with the porous media and hence by its own physical chemical properties $[13,14]$. In other words, assessing the mobility of such colloidal aggregates allows us to determine the fate of HMs in soil. Therefore, a structural characterization of the released phases and a definition of structural relations with metal affinity and with migration patterns in soil are needed. Starting from these premises, the present paper aims to investigate the effect of irrigation wastewater characteristics on the colloidal mediated transport of $\mathrm{Cd}, \mathrm{Cu}, \mathrm{Ni}$ and $\mathrm{Zn}$ in soil. The research is conducted on a standard soil, irrigated with a "real" wastewater effluent. The soil is packed in columns, and semi-saturation conditions are always maintained. To better understand the HMs transport mechanism according to the over-mentioned multi-phase model, several spectroscopic methods, such as ultraviolet-visible spectroscopy (UV-VIS), three dimensional excitation emission matrix spectrofluorimetry (3DEEM), proton nuclear magnetic resonance spectroscopy $\left({ }^{1} \mathrm{H}-\mathrm{NMR}\right)$, are used to reach a deeper characterization of the organic metal binding phases.

\section{Materials and Methods}

\subsection{Leaching Experiments}

A micro-contamination phenomenon was reproduced and studied at laboratory scale, simulating the irrigation of an artificial soil with either the effluent collected from a wastewater treatment plant (WWTP) or a synthetic water containing four trace HMs in the same concentrations as in the real treated wastewater. To evaluate the dynamics of accumulation of micropollutants as well as their migration in the leachate, HMs concentrations were determined daily in the leachate and at the end of the 
experiment in the soil column matrices. The mobilization of humic substances in soil was monitored by determining the concentration of total phenols. The release of organic substances in the leachates was measured as chemical oxygen demand (COD) and Ultra-Violet (UV) absorbance. Leached organic matter was further characterized through 3DEEM spectrofluorimetry and NMR spectroscopy.

The used standard soil was prepared according to the "recipe" described in the guidelines of the Organization for Economic Cooperation and Development (OECD) [15]. These guidelines were developed in order to test the eco-toxicity of inorganic and organic chemicals in soil, therefore the OECD soil is widely used to test complex solid samples. The reference soil was composed of the following: kaolinite, $20 \%$; quartz sand, $74 \%$; $\mathrm{CaCO}_{3}, 1 \%$; sphagnum peat, $5 \%$. Kaolinite, quartz sand and $\mathrm{CaCO}_{3}$ were purchased from Sigma-Aldrich (USA). Sphagnum peat was obtained from a local gardening store. As the OECD itself indicates, the ability to retain or release contaminants is related to the amount of organic matter (peat) contained in the soil [15]. Before use, the soil was analyzed in the single components to define the background levels of the tested metals. Results of analysis are reported in Table 1. A very high concentration of $\mathrm{Pb}$ was found in the kaolinite.

The experimental tests were conducted at laboratory scale using treated wastewater (W1), sampled from a conventional activated sludge WWTP located near Paris (France). W1 was characterized in terms of metal content. The HMs concentrations were well below the threshold values suggested by Food and Agriculture Organization of the United Nations (FAO) in the wastewater quality guidelines for agricultural use [16]. On the basis of the obtained results, an artificial effluent (W2) containing the same concentrations of $\mathrm{Cd}, \mathrm{Cu}, \mathrm{Ni}$ and $\mathrm{Zn}$ but no dissolved organic matter (DOM) or other major elements was prepared. In details $\mathrm{W} 2$ was obtained dissolving analytical grade $\mathrm{CuCl}_{2} \cdot 2 \mathrm{H}_{2} \mathrm{O}$ (Carlo Erba Reagenti, Cornaredo, Italy), $\mathrm{NiCl}_{2} \cdot 6 \mathrm{H}_{2} \mathrm{O}$ (Sigma-Aldrich, Saint Louis, MO, USA), and $\mathrm{ZnCl}_{2}$ (Applichem, Gatersleben, Germany) and analytical standard Cd (Carlo Erba Reagenti, Italy), in analytical grade $\mathrm{HNO}_{3} 1 \%$ (J.T. Baker, Center Valley, PA, USA) solutions. The obtained stock solutions, containing $1 \mathrm{~g} / \mathrm{L}$ of the selected metal, were successively diluted with ultrapure water (Elgalab Option $\mathrm{Q}$, Elga-Veolia, Saint Maurice, France) to obtain the required concentrations. Final $\mathrm{pH}$ was adjusted to 6.8, adding a few drops of $\mathrm{KOH} 0.05 \mathrm{M}$. HMs concentrations in W1 and W2 are reported in Table 1.

Table 1. Characteristics of W1, W2 and OECD soil.

\begin{tabular}{cccc}
\hline Parameter & OECD Soil $(\mathbf{m g} / \mathbf{K g})$ & W1 $(\mu \mathrm{g} / \mathrm{L})$ & W2 $(\mu \mathrm{g} / \mathrm{L})$ \\
\hline $\mathrm{Al}$ & & 118 & - \\
$\mathrm{Ca}$ & 0.0363 & $1.11 \times 10^{5}$ & - \\
$\mathrm{Cd}$ & & 0.232 & 0.25 \\
$\mathrm{Co}$ & $<0.5$ & - \\
$\mathrm{Cr}$ & $\mathrm{ND}$ & - \\
$\mathrm{Cu}$ & 23.827 & 8.73 & 10 \\
$\mathrm{~K}$ & & $8.62 \times 10^{2}$ & - \\
$\mathrm{Mg}$ & & $1.34 \times 10^{5}$ & - \\
$\mathrm{Mn}$ & & 153 & - \\
$\mathrm{Na}$ & & $3.5 \times 10^{5}$ & - \\
$\mathrm{Ni}$ & 1.31 & 1.5 \\
$\mathrm{~Pb}$ & & $\mathrm{ND}$ & - \\
$\mathrm{Si}$ & 1.525 & & - \\
$\mathrm{Sr}$ & 499.3 & 928 & 25 \\
$\mathrm{Zn}$ & 2530 & 24.82 & 6.8 \\
$\mathrm{pH}$ & 89.0 & 6.8 & - \\
\hline DOM & 7.6 & $6.71 \times 10^{3}$ & \\
\hline
\end{tabular}

The described solutions were used to irrigate the soil packed in a polypropylene conical tube, holed in the bottom and filled in the lower part with two layers of glass wool and a layer of glass beads, to avoid soil loss in the leachate. The scheme of the columns is described elsewhere [11]. The columns ( $5 \mathrm{~cm}$ depth) were fed with $20 \mathrm{~mL}$ of wastewater every $12 \mathrm{~h}$. All tests were performed in triplicate. 
The test lasted for 17 days. After this time both the soils, divided into 5 layers of $1 \mathrm{~cm}$ each, and the daily leachates were characterized in terms of metals and organic matter content. Since a very high concentration of $\mathrm{Pb}$ was detected in the kaolinite, $\mathrm{Pb}$ was monitored in the soil and in the leachate as a tracer of the clay silicates migration. Kaolinite was indeed the only source of $\mathrm{Pb}$ in the experiment (Table 1). Clay silicate migration in the leachate was also assessed by monitoring Si concentration in the leachates.

\subsection{Analytical Procedures}

Each soil layer and the "blank" soil were dried at $35^{\circ} \mathrm{C}$ until constant weight and homogenized. Aliquots of $1 \mathrm{~g}$ were mineralized in $15 \mathrm{~mL}$ of aqua regia using a Milestone (Shelton, CT, USA) Start $\mathrm{D}$ microwave digester. Leachates were collected daily and divided into two aliquots. The first aliquot was acidified with $3 \% \mathrm{HNO}_{3}$ for metals analysis. The concentrations of $\mathrm{Cd}, \mathrm{Cu}, \mathrm{Ni}, \mathrm{Pb}, \mathrm{Si}$ and $\mathrm{Zn}$, were measured by ICP-OES spectroscopy (Perkin Elmer Optima 8300, Waltham, MA, USA) and ICP-MS (Perkin Elmer Nexion 300, USA) operating in dual detector mode. The second aliquot was stored at $-20{ }^{\circ} \mathrm{C}$ for spectroscopic characterization. Once defrost, the UV-VIS absorbance at $245 \mathrm{~nm}$ and the COD were determined. Moreover 3DEEM and for some selected leachate samples the ${ }^{1} \mathrm{H}-\mathrm{NMR}$ spectra were recorded. The UV measurements were carried out using a Lambda3 UV-VIS spectrophotometer from Perkin Elmer (USA). COD was determined according to APHA [17] standard method 5220D. Total Phenols were determined by Folin-Ciocalteau colorimetric assay. COD and total phenols absorbance readings were performed by means of a Photolab 6600 UV-VIS spectrophotometer (WTW, Weilheim, Germany). The 3DEEM matrices were acquired through the spectrofluorimeter Perkin Elmer LS 45 (USA). Excitation wavelength was varied between 210 and $450 \mathrm{~nm}$; emission wavelength was recorded between 370 and $585 \mathrm{~nm}$. NMR spectra were acquired on an AVANCE 400 NMR spectroscope (Bruker-BioSpin, Billerica, MA, USA), equipped with Prodigy cryo-probe. Solvent suppression was achieved using a standard pre-saturation sequence.

\section{Results}

\subsection{Mobility Profiles in Soil}

The results of metals analysis in the soil and in the leachate are summarized in Figure 1. Figure 1 also displays phenol concentration in the different soil layers to give an indication of organic material distribution and mobility.

The distributions of $\mathrm{Pb}$ and total phenols were very similar. Peaks of both concentrations were observable at the same depth. $\mathrm{Pb}$ and phenols together showed different trends in soil irrigated with $\mathrm{W} 1$ and W2. In the experiments conducted using W1 as irrigation water (W1 tests) total phenols and $\mathrm{Pb}$ concentrations showed two peaks, located at 2 and $4 \mathrm{~cm}$ depth. Overall $\mathrm{Pb}$ concentration was quite uniform, and accounted for almost one half of the initial background value. In the experiments conducted using W2 as irrigation water (W2 tests) there was a clear increase of the phenols and $\mathrm{Pb}$ concentrations which started below $3 \mathrm{~cm}$ of depth. At $6 \mathrm{~cm}$ depth, $\mathrm{Pb}$ concentration was very similar to the initial background value $(509 \mathrm{mg} / \mathrm{Kg}$ ). This is an illustration of a slow colloidal front that was still present at $4 \mathrm{~cm}$ depth at the end of the W2 tests. A different migration rate of the soil colloids, which moved faster in the soil irrigated with W1, was evidenced. According to the observed mobilization, $\mathrm{HMs}$ behaved differently in the two experiments. $\mathrm{Cu}$ distribution was very similar to $\mathrm{Pb}$ and phenols. In $\mathrm{W} 2$ tests, in fact, there was an evident accumulation below $3 \mathrm{~cm}$ depth, while in $\mathrm{W} 1$ tests the concentration presented two small peaks at 2 and $4 \mathrm{~cm}$ depth. Very little $\mathrm{Cu}$ contamination was present in the top layer. Conversely $\mathrm{Cd}, \mathrm{Ni}$ and $\mathrm{Zn}$ always displayed a concentration peak in the top of the column. Accumulation of $\mathrm{Cd}$ at $0.5 \mathrm{~cm}$ depth was higher in $\mathrm{W} 2$ tests $(49.51 \mu \mathrm{g} / \mathrm{Kg})$ than in $\mathrm{W} 1$ tests $(23.35 \mu \mathrm{g} / \mathrm{Kg})$. Ni concentration in the top layer was higher in W1 tests $(3.03 \mathrm{mg} / \mathrm{Kg})$ than in W2 tests $(1.92 \mathrm{mg} / \mathrm{Kg})$. The same behavior was observed for $\mathrm{Zn}(274$ and $189 \mathrm{mg} / \mathrm{Kg}$ in W1 and W2, respectively). However, quite high standard deviations were observed among the replicates in the case 
of $\mathrm{Ni}$ and $\mathrm{Zn}$. In the deeper layers practically no peaks were observed in the soil irrigated with $\mathrm{W} 1$. In contrast, in the soil irrigated with $\mathrm{W} 2$, the concentration of $\mathrm{Cd}, \mathrm{Cu}, \mathrm{Ni}$ and $\mathrm{Zn}$ greatly increased below $3 \mathrm{~cm}$, in accordance with $\mathrm{Pb}$ and phenols mobilization. In contrast to other metals, $\mathrm{Ni}$ and $\mathrm{Zn}$ concentrations markedly decreased at $5 \mathrm{~cm}$ depth. At such depth, $\mathrm{Ni}$ and $\mathrm{Zn}$ concentration was indeed comparable to the initial background levels.

Due to the accumulation in the lower layers, higher HMs retention was generally observable in W2 tests compared to W1 tests.

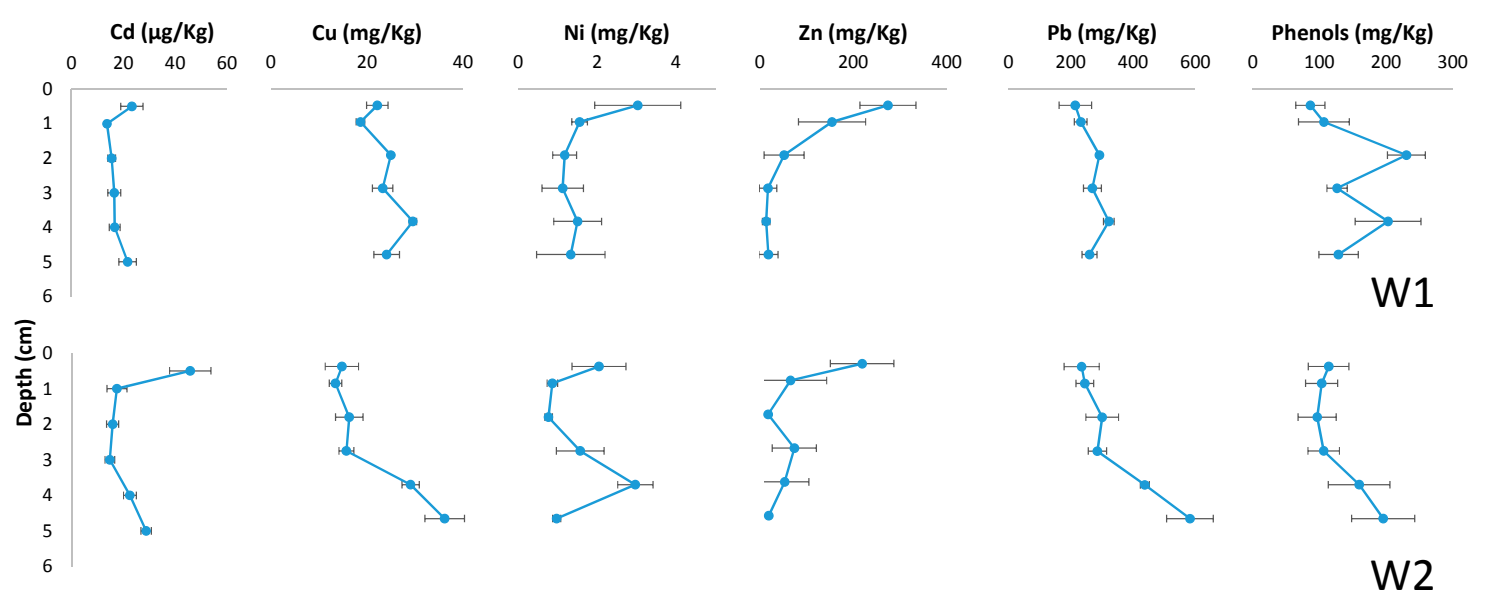

Figure 1. Metals and total phenols concentration in soil columns irrigated with W1 and W2. Irrigation lasted $17 \mathrm{~d}$ and a total leachate of $650 \mathrm{~mL}$ was collected at the end of the experiment. Soil background HMs concentrations are reported in Table 1.

\subsection{Leachates Characterization}

HMs mobilization information obtained from metal concentration in the different soil layers was confirmed by the concentration values of HMs detected in the leachates (Figure 2a). Obtained data showed that the irrigation with W1 led to higher mobilization of the colloidal silicates originating from kaolinite (Figure 2b). The release of $\mathrm{Si}$ was indeed around three times higher in $\mathrm{W} 1$ than with W2. This is reflected by higher metals release into the W1 leachate respect to one observed during the irrigation with W2.

The release of inorganic colloids and HMs in the leachate was indeed much higher during W1 tests (W1 leachate) than during W2 tests (W2 leachate). A remarkable difference between the two experiments was represented by the concentration of $\mathrm{Pb}$. In accordance with metal data in the soil columns (Figure 1) and Si trends (Figure $2 b$ ), a higher release was observed in W1 leachate where $\mathrm{Pb}$ concentration never went below $350 \mu \mathrm{g} / \mathrm{L}$. Conversely, W2 leachate displayed a decreasing trend of $\mathrm{Pb}$, which, at the end of the experiment, was stabilized near $100 \mu \mathrm{g} / \mathrm{L}$. Generally, HMs did not show a constant concentration in the leachates and several peaks were observable at given experimental times. In detail, peaks of metals were observed at the same time (days 8-10 and days 14-16) in both W1 leachate and W2 leachate. In W2 leachate, differently from W1 leachate, Zn concentration peaks were not observed, and $\mathrm{Zn}$ concentration remained constant in time, ranging between 20 and $40 \mu \mathrm{g} / \mathrm{L}$. High concentration of $\mathrm{Zn}$ and $\mathrm{Cu}$ was also recorded together in W1 leachate (day 11). In the same day, $\mathrm{Pb}$ released in the leachate also showed a marked increase. These peaks were not observable in $\mathrm{W} 2$ leachate. Ni mainly eluted with the other metals during days 8-10 in both the experiments.

Contemporarily with metal release, a constant release of organic matter in the leachate was observed, as indicated by UV $\mathrm{A}_{245}$ trend, reported in Figure 2c. $\mathrm{A}_{245}$ peaks were popping up at the same time (days 8-10 and days 14-16) as the major of HMs peaks (Figure 2a). At the same experimental time, peaks of $S i$ in W2 leachate were noticeable in Figure 2b. 
$\mathrm{COD}$ in the leachates displayed a trend very similar to $\mathrm{A}_{245}$ (data not shown). Also, in the case of $\mathrm{COD}$, relative maximum peaks (up to $68.5 \mathrm{mgO}_{2} / \mathrm{L}$ ) appeared at the same experimental time as $\mathrm{A}_{245}$ and metals peaks. A constant background release of COD was also recorded $\left(\approx 30 \pm 4 \mathrm{mgO}_{2} / \mathrm{L}\right)$.
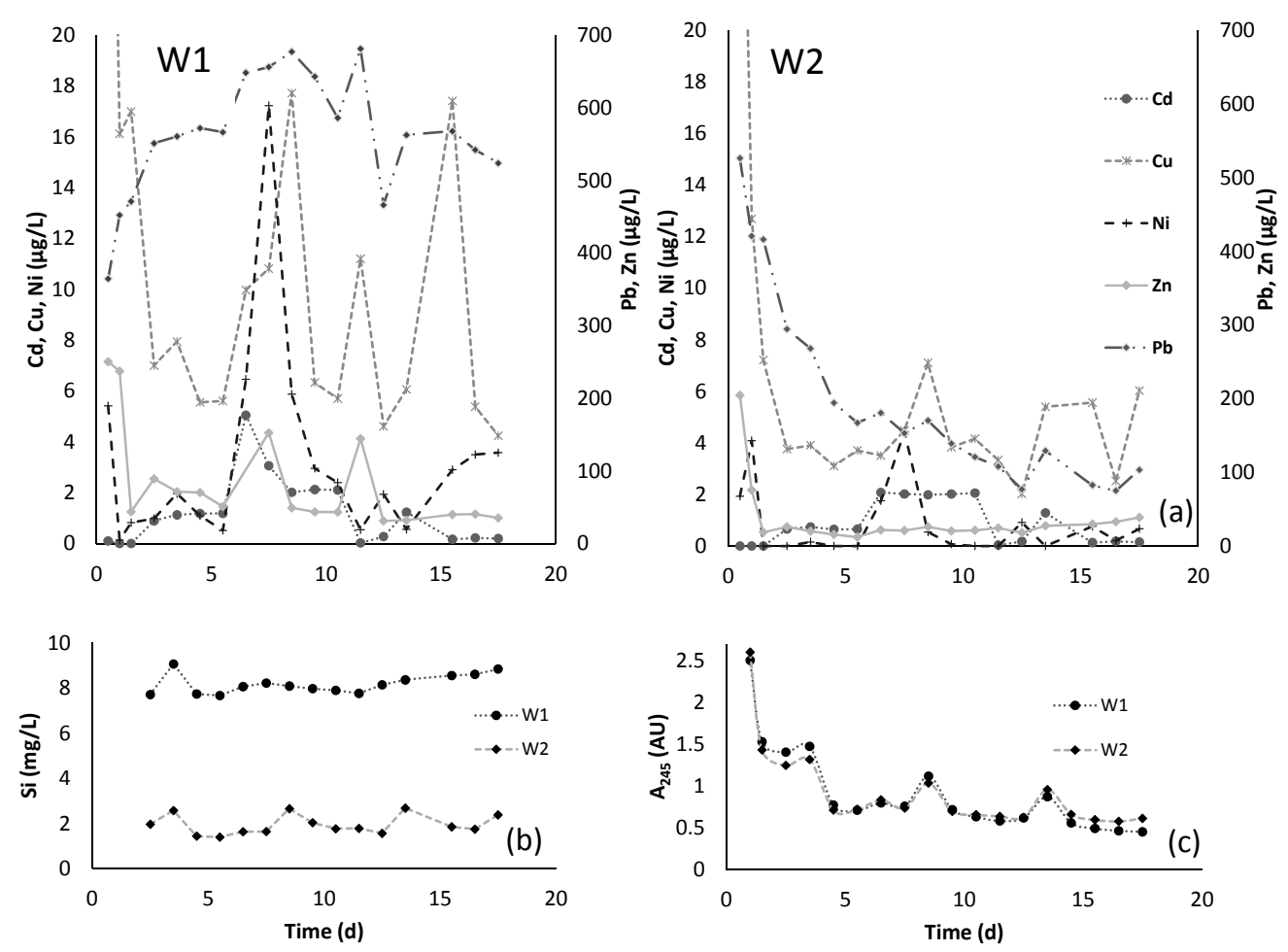

Figure 2. Evolution versus time of HMs (a); $\mathrm{Si}(\mathbf{b})$ concentrations and $\mathrm{A}_{245}(\mathbf{c})$ in the leachate produced by soil irrigation with $\mathrm{W} 1$ and $\mathrm{W} 2$. Time is expressed in days (d).

Correlation diagrams between total $\mathrm{HMs}$ (i.e., $\mathrm{Cu}, \mathrm{Cd}, \mathrm{Ni}, \mathrm{Zn}$ ) and $\mathrm{A}_{245}$ are plotted in Figure 3 for both experiments. A better correlation was achieved for $\mathrm{W} 2$ tests respect to $\mathrm{W} 1$ tests. The slope coefficient instead was higher in W1 tests. This latter result indicated that the interaction between the organic matter and the metals was more effective in W1 experimental condition, meaning that other factors played a significant role in determining overall metal mobilization by DOM.

W1

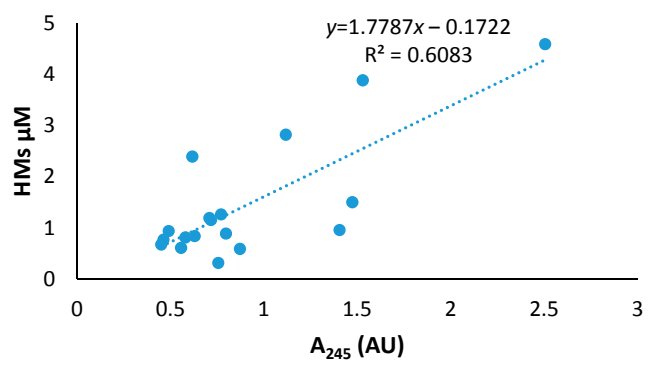

W2

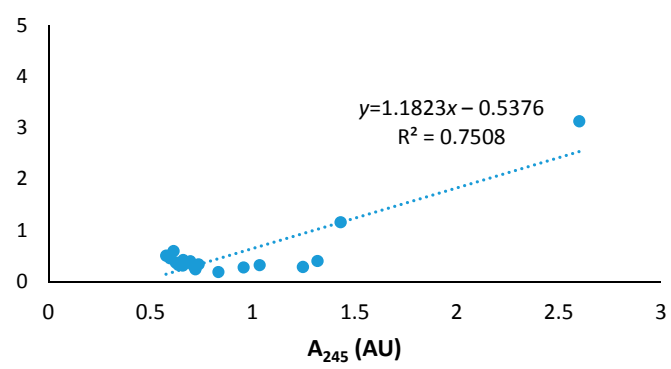

Figure 3. Correlation diagrams between HMs and $\mathrm{A}_{245}$ in the leachates.

\subsection{Spectroscopic Characterization of Released Soil Colloids}

A qualitative characterization of the organic substances was achieved by the excitation emission matrices of the leachates, presented in Figure 4. Figure 4 reports the contour plots related to leaching time from day 7.5 to day 9.5, corresponding to the previously described peaks of HMs. 
In most of the collected samples, the leachate presented a fluorescence matrix very similar to the one shown for the day 7.5. It was possible to observe two notable fluorescence peaks, corresponding, respectively to fulvic acids (ex230-em440) and humic acids (ex330-em445) [18]. Such a result confirmed that a continuous and constant release of organic substances from the soil to the liquid phase (background) took place during the experiments. A fluorescence peak (ex385-em460) appeared again at day 8.5 in both $\mathrm{W} 1$ and $\mathrm{W} 2$ tests. This peak identified a net change in the quality and quantity of DOM released into the leachate. The variation led to an increase of the absorption wavelength and consequently a slight increase of the emission wavelength compared to the previously mentioned background signal. The displacement was attributable to the presence of higher conjugation in the aromatic system as well as to the presence of auxochromes functional groups. The increase in ex-em wavelengths was also associated with higher molecular weight distribution and "humic" character of the fluorophores $[19,20]$.

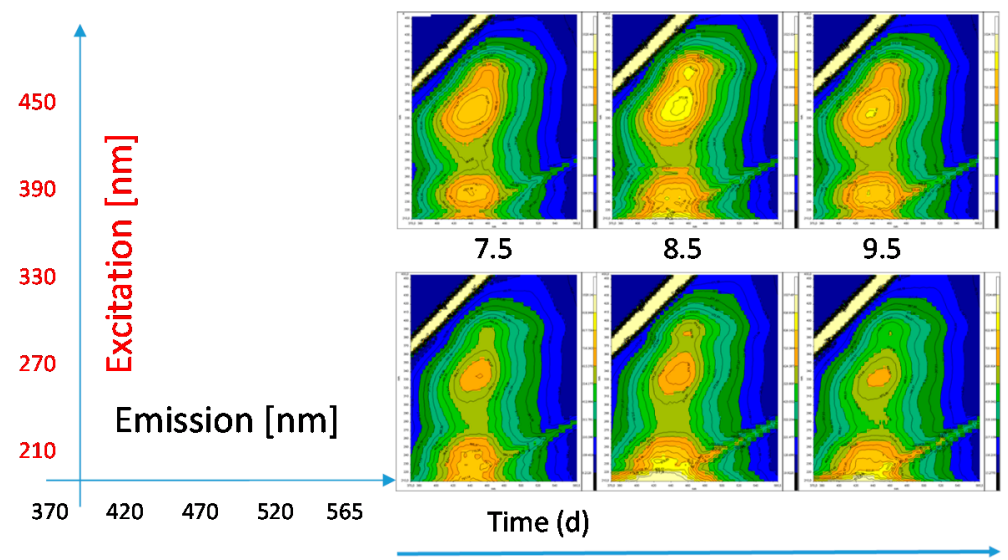

IW1

IW2

Figure 4. Selection of 3DEE matrices recorded in W1 and W2 leachates at time between 7.5 and 9.5 days.

Further information was obtained via the ${ }^{1} \mathrm{H}-\mathrm{NMR}$ spectra of the leachates collected at days 6.5, 8.5, 9.5, plotted in Figure 5. It was possible to observe the higher intensity of the signals in the sample relative to day 8.5, in agreement with the peak observed in the fluorescence matrix (Figure 4), confirming the peak of organic matter release in the leachate (Figure 3). The spectrum recorded on day 8.5 displayed high intensity signals in the aliphatic region $(1<\delta<1.8 \mathrm{ppm})$. A singlet signal was noticeable in the region of organo-silanes $(\delta=0.150 \mathrm{ppm})$. Several signals were observable (8.5 days) within the carbohydrates region $(3<\delta<6 \mathrm{ppm})$. Two signals of anomeric carbons were barely visible $(5.5<\delta<6 \mathrm{ppm})$, suggesting the presence of polysaccharides. These signals absent or much less intense in the other days samples confirmed that the quality of the organic matter release was changing over time. It is noticeable that the presence of carbohydrates was recorded in significant concentrations at experimental time corresponding to metal accumulation. At first glance, no peak was present in the aromatic region $(6<\delta<8 \mathrm{ppm})$ since the spectrum was not opportunely resolved (see magnification in Figure 5). Signals in this chemical shift region resulted in broadened line shapes with very low intensities. 


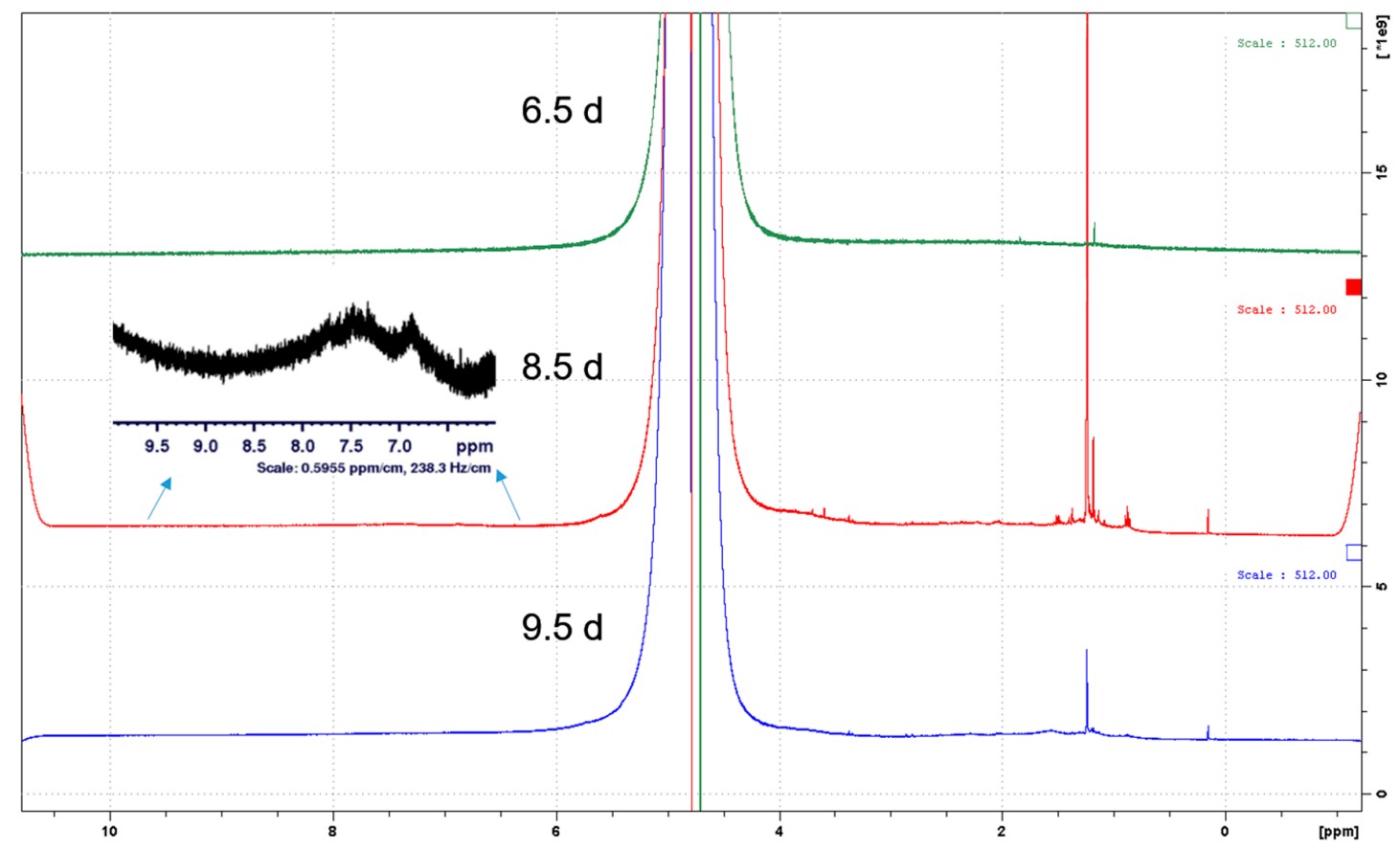

Figure 5. $400 \mathrm{MHz}{ }^{1} \mathrm{H}-\mathrm{NMR}$ spectra of collected leachates in correspondence of metals accumulation (days 6.5, 8.5, 9.5). Spectra were acquired with 20,480 scans, probe temperature of $298 \mathrm{~K}$, and solvent suppression with pre-saturation field of $50 \mathrm{~Hz}$.

\section{Discussion}

\subsection{Colloidal Mobilization of HMs}

By comparing Figures 1-5, it was evident that colloids containing organic molecules of a humic nature and/or their association with inorganic kaolinite platelets were involved in the transport of metals. These aggregates, generated in the soil, migrated through the column layers with a different moving rate compared to the water flow. Colloidal fronts were generated through the soil depth profile as indicated by the migration profiles of $\mathrm{Pb}$ and total phenols in soil and by the simultaneous release in the leachate of organic and inorganic matter, forming stable complexes with the metals (Figures 1 and 2). The similar distribution of the two parameters inside the soil strongly suggests the formation of colloidal MOAs moving at a rate influenced by: (i) the wastewater different salinity; (ii) the presence of DOM; and (iii) their own characteristics (i.e., amount of organic matter, humification degree, hydrophobicity, amount of polar/charged groups, molecular weight distribution, stability of the supramolecular structure). A previous study [11] reported a decreasing colloidal mobilization speed at increasing sodium content. In this study, although W1 had a consistent concentration of $\mathrm{Na}$ (350 mg/L) while W2 had none, the colloids migration rate was higher for W1 than W2. The effect of sodium ions was therefore different from that of general "salinity". Ca and $\mathrm{Mg}(111$ and $134 \mathrm{mg} / \mathrm{L}$ in W1, respectively), with a lower ionic radius and divalent charge and hence more concentrated charge distribution than sodium, did not increase the clay dispersion. In contrast, they facilitated the aggregation of clay particles, keeping soil flocculated and competing with sodium for binding sites [21-23]. This effect overrode the sodicity influence, resulting in higher colloidal mobilization in soil irrigated with $\mathrm{W} 1$ as ascertained by the Si trend reported in Figure $2 \mathrm{~b}$.

Also, the presence (W1 test) / absence (W2 test) of DOM caused different mobility. During W2 tests, zinc concentration peaks, characteristics of W1 tests, were not observed (Figures 1 and 2). Two different explanations are proposed: (i) Zinc from the real wastewater was already present as bound to different transport molecules (DOM) upstream to the interaction with the organic substance of the soil; (ii) Zinc had high affinity to immobile matrix as confirmed by the high concentration in the first $0.5 \mathrm{~cm}$ (Figure 1). 
The lower colloids release allowed by W2 irrigation made the mobilizable fraction of $\mathrm{Zn}$ to reach only $3 \mathrm{~cm}$ depth at the end of the experiment. The same $\mathrm{Zn}$ fraction was mobilized earlier within the leachate (Figure 2a) during the irrigation with W1, which was characterized by an enhanced colloidal mobilization. Such a result highlighted how the mobility of metals was not only dependent on the characteristics of the soil, but also strongly correlated to the speciation of the metals themselves within both the irrigation and the pore water [24].

\subsection{Role and Nature of Colloidal Aggregates}

Under the tested experimental conditions, DOM seemed to act as metal carrier through the soil column. This assumption was confirmed by the monitoring of UV absorbance of the leaching solution. The presence of both $\mathrm{A}_{245}$ (Figure 2c) and COD backgrounds was due to the release of organic molecules, as already described in a previous study [11]. The origin of the observed organic matter was attributed to soil release phenomena. Absorbance and COD backgrounds were present even in the W2 solution that was devoid of any source of DOM (Table 1). The presence in W2 of peaks of $\mathrm{Si}$ simultaneously to $\mathrm{A}_{245}$ (Figure $2 \mathrm{~b}, \mathrm{c}$ ) reinforced the hypothesis of aggregation of the detected organic matter with kaolinite platelets. Clearly, the presence of DOM is not the sole parameter influencing metal release in the leachate, and coefficients of correlation in Figure 3 were quite far from 1. Nevertheless, the trend was clearly observable and it was possible that metals were released together with organic matter into the leachate. Salinity played a major role in enhancing the dispersion of data in the W1 test, which were characterized by a lower value of $\mathrm{R}^{2}$ (Figure 3 ). On the other side, the higher value of the slope in W1 meant that in presence of salinity, DOM mobilization of metals was "more effective". Obviously $\mathrm{A}_{245}$ is an indirect measure of DOM and does not give information about the quality of organic matter and this is another reason for the observed data dispersion. As discussed below, molecular characterization of DOM, and in detail its structure, aggregation state, humification degree, molecular weight distribution, presence of metal chelating functional groups are all factors that influence the interaction with HMs [20,25]. From the observation of 3DEEM (Figure 4) it was clear that at the experimental time corresponding to the metal accumulation, the features of the organic substance in the leachate were significantly different from the background. This means that the quality of the released humic and fulvic substances was changing over time. Several studies have shown quenching of fluorescence related to metals and mainly $\mathrm{Cu}$ binding to HA-like fluorophores $[19,26]$. In the collected leachates, $\mathrm{Cu}$ concentration was never above $1 \mu \mathrm{M}$ and the quenching due to $\mathrm{Cu}$ could not be higher than $10 \%$ of the total fluorescence intensity [18]. The lower fluorescence intensity in W2 leachate was hence attributable to the mobilization of total phenols, clearly indicated in Figure 1: less humic matter mobilized in the W2 test. ${ }^{1} \mathrm{H}-\mathrm{NMR}$ spectra further confirmed the heterogeneity over time of the released organic matter. The hypothesis made about the formation of MOAs was emphasized by the silanic signal (Figure 5, 8.5 days) at high fields, suggesting also the formation of covalently bound aggregates. The presence of aliphatic signals was in accordance with the fluorescence observed at low excitation wavelengths (fulvic acids area). Although very high fluorescence is observable in the humic area (Figure 4), aromatic signals displayed very low intensity and poor resolution in all the acquired NMR spectra. This was ascribed to the supramolecular structure of the colloidal humic substances detected. The aggregate was hence stabilized by the aromatic moieties, which strongly interacted, forming a very stable hydrophobic core of the colloidal micelle. The polar residues (i.e., carbohydrates, O-Alkyl groups, amines) were instead exposed to the water phase and as a result were easily detectable by NMR. This type of structure indeed caused the protons contained within the micelles to have different relaxation times, which resulted in broad unresolved peaks. Such behavior has already been reported in literature [27], suggesting that the broadening of line shapes might be due mainly two factors: aggregation state of the molecules and interaction with paramagnetic metals or a combination of both effects. Both hypotheses are in good agreement with data obtained in this work. This indicates that the released organic matter was in form of colloidal supramolecular aggregates, with a very stable micellar structure and very high heterogeneity. 


\subsection{Comparison of Results with the Literature}

The main observation of this study is that trace HMs mobility in soil was driven by colloidal mobilization. Such behavior was already qualitatively described in literature [28], and several studies reported that metal mobility was severely affected by colloidal mobilization in the case of HMs at $\mu$ moles level $[13,23,29]$. Generally it is very difficult to compare data, since experiments were carried out at different concentrations and soil colloids are in general poorly characterized and potentially very heterogeneous. For instance, Pédrot, et al. [14] divided trace metals into three groups according to their interaction with colloids. $\mathrm{Cu}, \mathrm{Ni}$, and $\mathrm{Zn}$ were catalogued within the same group of metals influenced by organic rich colloids. From Figure 1 it was possible to conclude that $\mathrm{Cu}, \mathrm{Ni}$ and $\mathrm{Zn}$ behaved differently from each other. $\mathrm{Cu}$ showed a strong affinity with the slow colloidal phases that were moving within the soil, since its profile in Figure 1 was very similar to that displayed by $\mathrm{Pb}$ and phenols. No accumulation of $\mathrm{Cu}$ was detected in the top layer. $\mathrm{Ni}$ and $\mathrm{Zn}$, conversely, accumulated in the top layer (depth $0.5 \mathrm{~cm}$ ). On one hand, all metals interacted with the slow colloidal front at depth below $3 \mathrm{~cm}$. On the other hand, in the W1 test they eluted together (Figure 2) at day 8.5 into the leachate. After 10.5 days, only $\mathrm{Ni}$ and Zn eluted, and after 15 day, only $\mathrm{Cu}$. As mentioned before, no Zn peak was detected in W2 and again, only Cu eluted after 15 days. Even in the simplified model of the OECD artificial soil, different kinds of colloids were generated in different boundary conditions (Figures 4 and 5), each with its own moving rate and affinity to specific metals. This did not exclude in general the interaction with organic rich colloids as reported by the cited literature, but highlighted the huge heterogeneity of mobility patterns that are possible for metal-colloid complexes. Several studies are available in the literature concerning interaction of metals with organic and inorganic matter [19,30-33]. Although the majority of them deal with case studies on real scale or with higher concentration ranges, some comparisons are still possible with the obtained results. It was reported that low molecular weight organic acids in soils were released after the partial degradation of soil organic matter [34]. Simple organic acids, dissolved or aggregated in humic supramolecular structures [12,35], enhanced metal mobility in soil profiles by reducing soil $\mathrm{pH}$ and forming complexes with heavy metals [36]. The investigation by thin layer chromatography (TLC) of $\mathrm{Zn}, \mathrm{Cd}$ and $\mathrm{Pb}$ mobility in a sandy loam soil in presence of aqueous solutions of several organic acids, enhanced the transport of heavy metals, especially $\mathrm{Zn}$ and $\mathrm{Cd}$. Although $\mathrm{Pb}$ was slightly mobilized by citric and tartaric acids, it was found that this metal formed stable complexes with organic acids which strongly interacted with inorganic soil matrix resulting in little mobility [37]. It was observed that $\mathrm{Cd}$ mobility decreased with increasing of soil organic matter, while it increased with the increasing of salinity and dissolved organic matter [38] in accordance to the results of the present study. $\mathrm{Cd}, \mathrm{Pb}$ and $\mathrm{Zn}$ were completely immobilized by the soil matrix, mostly to the acid-soluble fraction, in the first few centimetres of the soil, while in the leachates $\mathrm{Cd}$ behaved differently from other metals, due to the marked difference in adsorption kinetics [39]. According to another study, depth penetration of Cd into the soil profile took place due to the preferential paths through macropores. It was reported that colloids might have blocked the soil matrix capillary, which led to the final accumulation of $\mathrm{Cd}$ in the first $0.5 \mathrm{~cm}$. In contrast, the application of DOM increased the diffusion of $\mathrm{Cd}$, as observed in this study [40]. Metal mobility was hence affected by very complex equilibria in which the interaction with colloids and nanoparticles played a prominent role in determining their fate in the soil. Further studies are, of course, needed to achieve a deeper knowledge of the humic supramolecular structures and their aggregation with inorganic colloids as well as the interaction that this complex transport media has with contaminants, even at trace concentrations.

\section{Conclusions}

Trace HMs mobilization in soil is controlled by colloidal mobilization. Colloids, which might be organic, inorganic or MOAs, are released from the soil matrix over time and act as a metal carrier, moving through the soil column with a lower velocity than the water flow (multiphase medium), selectively interacting with contaminants contained in the irrigation water. The result of this interaction 
is the generation of contamination fronts that move in the soil matrix at the pace of the colloidal phase and generate accumulation peaks of HMs in the leachate and in the soil layers. A direct correlation was found between the abundance of HMs in the leachate and the contemporary release of DOM, expressed as UV $A_{245}$. The organic molecules responsible for the mobilization, detected by UV-VIS measurements, were shown to belong to the class of humic and fulvic acids, as indicated by 3DEEM spectrofluorometric data. A very stable and strongly hydrophilic micellar structure was hypothesized for these molecules on the basis of ${ }^{1} \mathrm{H}-\mathrm{NMR}$ data. Colloidal aggregates seemed to be generated from the soil organic matter, since they were also detected in the leachate produced by irrigation with an artificial solution deprived of any dissolved organic matter. It was concluded that the transfer of pollutants in the complex water/soil system was not only related to the concentration of contaminants in the irrigation water, but also to the physical-chemical properties of the soil as well as the generated colloidal aggregates.

Acknowledgments: The authors would like to thank the European Commission for providing financial support through the Erasmus Mundus Joint Doctorate Program $\mathrm{ETeCoS}^{3}$ (Environmental Technologies for Contaminated Solids, Soils and Sediments) under the grant agreement FPA $n^{\circ}$ 2010-0009. This research was also conducted in the framework of the project "Emerging contaminants in soil and water: from source to marine environment" funded by the Italian Ministry of Education, University and Research (MIUR) in the context of the Research Programs of National Interest (PRIN) 2010-2011.

Author Contributions: Ludovico Pontoni, Eric D. van Hullebusch and Yoan Pechaud conceived and designed the experiments. Ludovico Pontoni performed the experiments, all the authors analyzed the data and cooperated in writing the paper, and Eric D. van Hullebusch, Massimiliano Fabbricino, Giovanni Esposito and Francesco Pirozzi contributed reagents/materials/analysis tools.

Conflicts of Interest: The authors declare no conflict of interest. The founding sponsors had no role in the design of the study; in the collection, analyses, or interpretation of data; in the writing of the manuscript, and in the decision to publish the results.

\section{References}

1. Ma, X.; Xue, X.; González-Mejía, A.; Garland, J.; Cashdollar, J. Sustainable water systems for the city of tomorrow-A conceptual framework. Sustainability 2015, 7, 12071. [CrossRef]

2. Chen, W.; Bai, Y.; Zhang, W.; Lyu, S.; Jiao, W. Perceptions of different stakeholders on reclaimed water reuse: The case of beijing, china. Sustainability 2015, 7, 9696-9710. [CrossRef]

3. Ilias, A.; Panoras, A.; Angelakis, A. Wastewater recycling in greece: The case of thessaloniki. Sustainability 2014, 6, 2876-2892. [CrossRef]

4. Lu, J.; Wilson, P.C.; Wen, X.; Jin, Q.; Wu, J. Harmful chemicals in the environment: Measurement, fate, and remediation. J. Chem. 2015, 2015, 723749. [CrossRef]

5. Nunes, J.; Ramos-Miras, J.; Lopez-Piñeiro, A.; Loures, L.; Gil, C.; Coelho, J.; Loures, A. Concentrations of available heavy metals in mediterranean agricultural soils and their relation with some soil selected properties: A case study in typical mediterranean soils. Sustainability 2014, 6, 9124. [CrossRef]

6. Dixit, R.; Malaviya, D.; Pandiyan, K.; Singh, U.B.; Sahu, A.; Shukla, R.; Singh, B.P.; Rai, J.P.; Sharma, P.L.; Lade, H.; et al. Bioremediation of heavy metals from soil and aquatic environment: An overview of principles and criteria of fundamental processes. Sustainability 2015, 7, 2189. [CrossRef]

7. Weng, L.; Fest, E.P.; Fillius, J.; Temminghoff, E.J.; van Riemsdijk, W.H. Transport of humic and fulvic acids in relation to metal mobility in a copper-contaminated acid sandy soil. Environ. Sci. Technol. 2002, 36, 1699-1704. [CrossRef] [PubMed]

8. McGechan, M.; Lewis, D. Sw—Soil and water: Transport of particulate and colloid-sorbed contaminants through soil, part 1: General principles. Biosyst. Eng. 2002, 83, 255-273. [CrossRef]

9. Kleber, M.; Eusterhues, K.; Keiluweit, M.; Mikutta, C.; Mikutta, R.; Nico, P.S. Mineral-organic associations: Formation, properties, and relevance in soil environments. Adv. Agron. 2015, 130, 1-140.

10. Ryan, J.N.; Elimelech, M. Colloid mobilization and transport in groundwater. Colloids Surf. A Physicochem. Eng. Asp. 1996, 107, 1-56. [CrossRef] 
11. Pontoni, L.; van Hullebusch, E.D.; Fabbricino, M.; Esposito, G.; Pirozzi, F. Assessment of trace heavy metals dynamics during the interaction of aqueous solutions with the artificial oecd soil: Evaluation of the effect of soil organic matter content and colloidal mobilization. Chemosphere 2016, 163, 382-391. [CrossRef] [PubMed]

12. Piccolo, A. The supramolecular structure of humic substances: A novel understanding of humus chemistry and implications in soil science. Adv. Agron. 2002, 75, 57-134.

13. De Jonge, L.W.; Kjaergaard, C.; Moldrup, P. Colloids and colloid-facilitated transport of contaminants in soils. Vadose Zone J. 2004, 3, 321-325.

14. Pédrot, M.; Dia, A.; Davranche, M.; Bouhnik-Le Coz, M.; Henin, O.; Gruau, G. Insights into colloid-mediated trace element release at the soil/water interface. J. Colloid Interface Sci. 2008, 325, 187-197. [CrossRef] [PubMed]

15. Wilhelm, K.-P.; Maibach, H.I. Oecd guidelines for testing chemicals. In Dermatoxicology, 7th ed.; CRC Press: Boca Raton, FL, USA, 2008; pp. 303-305.

16. Pescod, M. Wastewater Treatment and Use in Agriculture; Nations, Ed.; Fao Irrigation and Drainage Paper 47 United; FAO: Rome, Italy, 1992.

17. American Public Health Association; American Water Works Association. Standard Methods for the Examination of Water and Wastewater; American Public Health Association: Washington, DC, USA, 1998.

18. Yamashita, Y.; Jaffé, R. Characterizing the interactions between trace metals and dissolved organic matter using excitation-emission matrix and parallel factor analysis. Environ. Sci. Technol. 2008, 42, 7374-7379. [CrossRef] [PubMed]

19. Boguta, P.; D'Orazio, V.; Sokołowska, Z.; Senesi, N. Effects of selected chemical and physicochemical properties of humic acids from peat soils on their interaction mechanisms with copper ions at various phs. J. Geochem. Explor. 2016, 168, 119-126. [CrossRef]

20. Boguta, P.; Sokołowska, Z. Interactions of $\mathrm{zn}(\mathrm{II})$ ions with humic acids isolated from various type of soils. Effect of ph, zn concentrations and humic acids chemical properties. PLoS ONE 2016, 11, e0153626. [CrossRef] [PubMed]

21. Warrence, N.J.; Bauder, J.W.; Pearson, K.E. Basics of Salinity and Sodicity Effects on Soil Physical Properties; Departement of Land Resources and Environmental Sciences, Montana State University-Bozeman: Bozeman, MT, USA, 2002.

22. Duan, R.; Sheppard, C.D.; Fedler, C.B. Short-term effects of wastewater land application on soil chemical properties. Water Air Soil Pollut. 2010, 211, 165-176. [CrossRef]

23. Kretzschmar, R.; Sticher, H. Transport of humic-coated iron oxide colloids in a sandy soil: Influence of $\mathrm{Ca}^{2+}$ and trace metals. Environ. Sci. Technol. 1997, 31, 3497-3504. [CrossRef]

24. Moreno-Jiménez, E.; Beesley, L.; Lepp, N.W.; Dickinson, N.M.; Hartley, W.; Clemente, R. Field sampling of soil pore water to evaluate trace element mobility and associated environmental risk. Environ. Pollut. 2011, 159, 3078-3085. [CrossRef] [PubMed]

25. Chen, Y.; Fabbricino, M.; Benedetti, M.F.; Korshin, G.V. Spectroscopic in situ examination of interactions of rare earth ions with humic substances. Water Res. 2015, 68, 273-281. [CrossRef] [PubMed]

26. Wu, F.C.; Mills, R.B.; Evans, R.D.; Dillon, P.J. Kinetics of metal-fulvic acid complexation using a stopped-flow technique and three-dimensional excitation emission fluorescence spectrophotometer. Anal. Chem. 2004, 76, 110-113. [CrossRef]

27. Lam, B.; Simpson, A.J. Direct $1 \mathrm{~h}$ nmr spectroscopy of dissolved organic matter in natural waters. Analyst 2008, 133, 263-269. [CrossRef] [PubMed]

28. McCarthy, J.F.; Zachara, J.M. Subsurface transport of contaminants. Environ. Sci. Technol. 1989, $23,496-502$. [CrossRef]

29. Klitzke, S.; Lang, F. Hydrophobicity of soil colloids and heavy metal mobilization. J. Environ. Qual. 2007, 36, 1187-1193. [CrossRef] [PubMed]

30. Covelo, E.F.; Vega, F.A.; Andrade, M.L. Competitive sorption and desorption of heavy metals by individual soil components. J. Hazard. Mater. 2007, 140, 308-315. [CrossRef] [PubMed]

31. Flogeac, K.; Guillon, E.; Aplincourt, M. Surface complexation of copper(II) on soil particles: Epr and xafs studies. Environ. Sci. Technol. 2004, 38, 3098-3103. [CrossRef] [PubMed]

32. Grybos, M.; Davranche, M.; Gruau, G.; Petitjean, P. Is trace metal release in wetland soils controlled by organic matter mobility or fe-oxyhydroxides reduction? J. Colloid Interface Sci. 2007, 314, 490-501. [CrossRef] [PubMed] 
33. Temminghoff, E.J.; van der Zee, S.E.; de Haan, F.A. Copper mobility in a copper-contaminated sandy soil as affected by $\mathrm{pH}$ and solid and dissolved organic matter. Environ. Sci. Technol. 1997, 31, 1109-1115. [CrossRef]

34. Sposito, G. The Chemistry of Soils; Oxford University Press: Oxford, UK, 2008.

35. Kelleher, B.P.; Simpson, A.J. Humic substances in soils: Are they really chemically distinct? Environ. Sci. Technol. 2006, 40, 4605-4611. [CrossRef] [PubMed]

36. Renella, G.; Landi, L.; Nannipieri, P. Degradation of low molecular weight organic acids complexed with heavy metals in soil. Geoderma 2004, 122, 311-315. [CrossRef]

37. Schwab, A.; Zhu, D.; Banks, M. Influence of organic acids on the transport of heavy metals in soil. Chemosphere 2008, 72, 986-994. [CrossRef] [PubMed]

38. Gerritse, R.G. Column-and catchment-scale transport of cadmium: Effect of dissolved organic matter. J. Contam. Hydrol. 1996, 22, 145-163. [CrossRef]

39. Plassard, F.; Winiarski, T.; Petit-Ramel, M. Retention and distribution of three heavy metals in a carbonated soil: Comparison between batch and unsaturated column studies. J. Contam. Hydrol. 2000, 42, 99-111. [CrossRef]

40. Li, Z.; Zhou, L. Cadmium transport mediated by soil colloid and dissolved organic matter: A field study. J. Environ. Sci. 2010, 22, 106-115. [CrossRef]

(C) 2016 by the authors; licensee MDPI, Basel, Switzerland. This article is an open access article distributed under the terms and conditions of the Creative Commons Attribution (CC-BY) license (http:/ / creativecommons.org/licenses/by/4.0/). 